\title{
Beneficios fiscales para pequeños productores de leche bajo los regímenes de tributación en Colombia
}

\section{Juliana Carolina Farfan Rodriguez, Hugo Alejandro Pérez Velásquez}

\author{
Facultad de Ciencias Contables, Corporación Universitaria Remington, Colombia
}

Los pequeños productores de bienes exentos se enfrentan a la disyuntiva de permanecer en la informalidad, en un régimen de no responsabilidad, o de responsabilidad frente al impuesto sobre el valor agregado (IVA) o régimen simple de tributación - SIMPLE. El mayor beneficio fiscal para ellos corresponde a la posibilidad de solicitar la devolución del IVA pagado en adquisición de insumos para su producción, que les representa un mayor costo o gasto. El propósito de la presente investigación es analizar dichos beneficios fiscales de manera comparada en cada uno de los regímenes de tributación que se han establecido en Colombia en el periodo de 1989-2020. Para ello, se utilizó la metodología de derecho comparado en función de los cambios normativos. De igual forma, se hace uso el método de acción participativa, pues posibilita el desarrollo de la investigación en una comunidad de pequeños productores de leche ubicados en el norte de Antioquia; en ese contexto, se identifica el grado de desconocimiento fiscal, el régimen en el que se encuentran, y la capacidad para hacer los cambios administrativos y contables necesarios para acceder a los beneficios fiscales como productores de bienes exentos. Con esto, se puede establecer la opción más beneficiosa para pequeños productores de leche frente al régimen tributario en Colombia.

Palabras clave: impuesto al valor agregado, beneficios fiscales, regímenes simplificados de tributación, pequeños productores de leche

\section{Tax benefits for producers of milk under the taxation regimes in Colombia}

Small producers of exempt goods face the dilemma of remaining in the informal sector, in a regime of no responsibility, or yes liability in front of VAT or SIMPLE regime; the greatest tax benefit for them corresponds to the possibility of requesting a refund of the VAT paid in the acquisition of inputs for their production, as a higher cost or expense; The purpose of this research is to analyze said tax benefits in a comparative way in each of the tax regimes that have been established in Colombia during 1989 -2020. For this, the comparative law methodology is used based on regulatory changes; Similarly, the participatory action method is used as it enables the development of research with a community of small milk producers located in the north of Antioquia, in which the degree of fiscal ignorance is identified, the regime in which the find and the ability to make the administrative and accounting changes necessary to access tax benefits as producers of exempt goods. With this, the most beneficial option for small milk producers can be established in relation to the tax regime in Colombia.

Keywords: value added tax, fiscal benefits, simplified taxation regimes, small milk producers 


\section{Benefícios fiscais para pequenos produtores de leite sob os regimes fiscais na Colômbia}

Os pequenos produtores de bens isentos enfrentam o dilema de permanecer no setor informal, em regime de isenção de responsabilidade face ao IVA ou regime SIMPLES; O maior benefício fiscal para eles corresponde à possibilidade de requerer a devolução do IVA pago na aquisição de insumos para a sua produção, que representou um custo ou despesa superior. O objetivo desta pesquisa é analisar esses benefícios fiscais de forma comparativa em cada um dos regimes fiscais que foram estabelecidos na Colômbia durante 1989-2020, Para isso, utiliza-se a metodologia do direito comparado com base nas mudanças regulatórias; Da mesma forma, o método de ação participativa é utilizado, pois permite o desenvolvimento de pesquisas com uma comunidade de pequenos produtores de leite localizada no norte de Antioquia. em que se identifica o grau de desconhecimento fiscal, o regime em que se encontram e a capacidade de efetuar as alteraçôes administrativas e contábeis necessárias ao acesso aos benefícios fiscais na qualidade de produtores de bens isentos. com isso, poder estabelecer a opçáo mais vantajosa para os pequenos produtores de leite contra o regime tributário da Colômbia.

Palavras-chave: imposto sobre valor agregado, benefícios fiscais, regimes tributários simplificados, pequenos produtores de leite

\section{Introducción}

Los pequeños productores del sector agrícola se caracterizan por su grado de vulnerabilidad en el ámbito económico, debido a la baja capacidad técnica, administrativa y financiera. Específicamente, el aspecto tributario es uno de los que más les genera preocupación por el desconocimiento y el temor a contraer una alta carga fiscal que ponga en riesgo la liquidez de su actividad económica. Esta situación motiva que gran parte de los pequeños productores prefieran mantenerse en la informalidad. Frente a ello, los regímenes simplificados de tributación constituyen una herramienta de política fiscal que, a partir de incentivos tales como la simplicidad o los beneficios tributarios, busca acoger en la formalidad a este tipo de contribuyentes. En relación con el impuesto al valor agregado (en adelante, IVA) en Colombia, los pequeños productores cuentan con un doble beneficio: la exención del impuesto y la posibilidad de solicitar la devolución del IVA pagado como mayor valor en costos y gastos. Para acceder a ello, deben cumplir ciertos requisitos especiales y estar en un régimen determinado de tributación.
El objetivo de la investigación es comparar los beneficios fiscales correspondientes a los diferentes regímenes simplificados que se han establecido en Colombia a los que pueden acceder los pequeños productores de bienes exentos frente al IVA, cuyas actividades económicas se clasifican en el sector agropecuario. Entre los objetivos específicos, se encuentran los siguientes: 1) diferenciar los beneficios fiscales que se han establecido en los regímenes simplificados de tributación en Colombia para productores de bienes exentos del IVA durante el período de 1989-2020, 2) realizar la caracterización económica de los pequeños productores de bienes exentos del IVA en el sector agropecuario, y 3) analizar de manera comparativa los beneficios asociados a cada tipo de régimen simplificado para establecer las situaciones más beneficiosas para los contribuyentes del sector agropecuario en términos económicos y fiscales.

La metodología utilizada en el proceso de investigación fue de derecho comparado como estrategia para analizar la norma fiscal de manera comparativa en función de los beneficios que se han establecido para 
este tipo de contribuyentes en los diferentes regímenes de tributación. El método de acción participativa se aplica con una población de pequeños productores de leche en el norte antioqueño. Dicho producto es considerado como un bien exento del IVA por la norma fiscal en Colombia. En la investigación, se utiliza la herramienta de la encuesta para identificar los conocimientos previos de la comunidad frente a la norma fiscal que los afecta, así como la capacidad para implementar los requisitos necesarios para acceder a los beneficios fiscales que les competen como pequeños productores de leche.

\section{Antecedentes}

En la revisión del estado del arte sobre los diferentes regímenes simplificados en América Latina y las condiciones normativas más deseables en términos de beneficios y costos, se identifican diversas posiciones y resultados que se pueden clasificar de la siguiente manera: descripción de regímenes simplificados, beneficios fiscales, costos fiscales, política fiscal y eficiencia en el recaudo. Así, frente a los regímenes simplificados en México, Chávez, Peña y Hernández (2015) analizan el régimen simplificado denominado "Régimen de Incorporación Fiscal”. Al respecto, se resaltan los costos que representan para los pequeños contribuyentes de las poblaciones más vulnerables cuando se incorporan a la formalidad; en alguna medida, esto se debe a los costos administrativos y contables, como la implementación de facturación electrónica. Por su parte, González y Sheila (2015) analizan el régimen de incorporación fiscal en México como una respuesta a los altos índices de evasión fiscal e informalidad, con el fin de facilitar el cumplimiento de la obligación a pequeños contribuyentes. Entre los principales beneficios que ofrece dicho régimen, se encuentra el acceso a servicios médicos, pensión y créditos de vivienda.
En el caso de México, los bienes y servicios que tienen tasa de $0 \%$ tienen derecho a solicitar la devolución del IVA incorporado a los costos de producción. Por otro lado, al carecer de responsabilidad frente al impuesto, los bienes y servicios exentos no cuentan con dicha posibilidad. En el estudio de González y Sheila (2015), se sustenta que los bienes de tarifa cero deben pasar a ser exentos del impuesto en mención para disminuir el costo fiscal que representa la devolución del IVA.

Por su parte, Gutiérrez y Tamayo (2017) consideran a las pymes como el motor de crecimiento económico en México. Por lo tanto, proponen un régimen fiscal que aporte la permanencia de este tipo de empresas en el mercado con mayores beneficios fiscales en los primeros ańos del desarrollo de su actividad económica. Además, resaltan la posibilidad de deducir el costo de ventas para la depuración del impuesto. Frente a ello, Nagamine, Duarte y Da Silva (2013) sustentan la necesidad de que los regímenes simplificados incorporen a los trabajadores por cuenta propia. Concretamente, Brasil ha sido el pionero en dar beneficios a este tipo de contribuyentes; con ello, la política fiscal aporta al fortalecimiento del mercado. Esto tiene implicaciones importantes al trasladarse al ámbito rural, en el que la mayoría de las explotaciones económicas se dan bajo la figura de trabajadores por cuenta propia.

Con respecto a las generalidades de la norma fiscal en América Latina, García, Torrejón, San Alverto y Del Blanco García (2010) comparan en su estudio los sistemas tributarios de América Latina. De ellos, se resalta el régimen simplificado para pymes y regímenes especiales de tributación para contribuyentes de menores recursos, que incluyen el impuesto a la renta y el IVA. En el caso de Brasil, se resalta también el régimen especial para agricultores, a los que se les permite reconocer una utilidad del $20 \%$ para efectos 
fiscales, además de la compensación de las pérdidas que hayan acontecido en años anteriores.

\section{La Organización Internacional del Trabajo (OIT,} 2014) estudia la implementación del monotributo en Argentina, Brasil y Uruguay. Se resalta el caso de Brasil, que incluye un régimen para los trabajadores rurales que ofrece la inclusión al sistema de seguridad social para disminuir las brechas de desigualdad entre las economías rurales y urbanas. Argentina también implementó un régimen simplificado dirigido a los pequeños productores agropecuarios, llamado "monotributo social”; con él, se les permite acceder a seguridad social y pensión. Lattuada (2008) también estudia la política agraria en el contexto de Argentina. Históricamente, el país se ha enfocado en promover las explotaciones productivas por medio de un impuesto único de acuerdo con las capacidades del terreno y condiciones climáticas favorables, basado en la progresividad como control de la especulación. Por su parte, Casella (2008) sustenta que los regímenes simplificados de tributación deben propender por la inclusión generalizada de los contribuyentes con diferencias socioeconómicas, bajo el cumplimiento de los principios tributarios; específicamente, propone modificar el monotributo en Argentina para un mayor cumplimiento del principio de equidad.

Con respecto a Chile, Poblete (2010) señala que las políticas tributarias más efectivas serían las que promuevan la disminución del IVA, que se vea compensado en un aumento del impuesto a la renta, dado que el primero permite una mejor equidad y redistribución del ingreso. En ese sentido, los regímenes simplificados deben contemplar beneficios con mayor impacto sobre el mejoramiento de la calidad de vida y las condiciones socioeconómicas de los contribuyentes. Un ejemplo de ello es resaltado por los Servicios de Impuestos Internos (SII, 2006), que identifican los beneficios de las obligaciones fiscales para el caso de los profesionales independientes en Chile, como lo es la deducción en el impuesto a la renta de las cuotas de garantía hipotecaria para la adquisición de vivienda; esto incluye a aquellos que desarrollan actividades agrícolas.

Por otra parte, Enciso y Roche (2006) realizan un análisis sobre los beneficios que ofrece el sistema tributario español a los contribuyentes que desarrollan sus actividades económicas en las zonas rurales, entre los cuales resalta la posibilidad de deducir el IVA soportado en sus operaciones. Sin embargo, se considera que la generalidad en los regímenes simplificados, y el régimen especial de agricultura, ganadería y pesca va en contra del principio de la equidad tributaria al no contemplar las situaciones económicas particulares de agentes rurales; por ello, podrían quedar fuera de la norma.

Con respecto a los beneficios fiscales, Arroyo (2013) realiza un estudio sobre el régimen tributario costarricense. Explica cómo se genera el crédito fiscal para los productores de bienes exentos en Costa Rica, como en el caso del beneficio tributario en el impuesto sobre las ventas. El tema se aborda desde el punto de vista operativo. El sistema de deducción financiera plena busca que el productor pueda reconocer el valor del impuesto soportado en la etapa productiva; así, no se afecta el costo y aumenta la rentabilidad de los productores por el reconocimiento fiscal de la deducción. Por su parte, el Banco Interamericano de Desarrollo (2006) resalta, entre los principales beneficios tributarios en América Latina, la menor carga tributaria, y la cobertura en pensiones y salud para poblaciones con bajos ingresos. De igual manera, se menciona que uno de los mayores riesgos es el enanismo fiscal como mecanismo de evasión, utilizado por pequeños contribuyentes que adaptan la información económica con 
el fin de evidenciar condiciones económicas menos favorables a las reales.

Entre las principales reflexiones acerca de las políticas fiscales orientadas a pequeños contribuyentes, $y$ las dificultades de recaudo y consecuentes disminuciones de ingresos tributarios que implican los beneficios a contribuyentes, se encuentra la investigación de Engel (2003). Este sostiene que, en la recaudación de impuestos, las políticas tributarias son poco efectivas en la redistribución del ingreso, a diferencia del gasto público. Además, promueve un aumento de las tarifas del IVA que vaya acompañado de mayor inversión social. Por su parte, Fuentes y Zamudio (2011) plantean que los tratamientos preferenciales del sistema tributario disminuyen el recaudo del Estado; además, dichos beneficios son aprovechados en mayor medida por los contribuyentes de mayores ingresos por la capacidad que tienen los mismos de conocer y aplicar la norma.

Frente a la norma fiscal, Guerrero (2015) propone que las estructuras tributarias ofrezcan beneficios a los pequeños contribuyentes sin discriminar los tipos de actividad económica. Además, plantea disminuir los altos costos administrativos que exige el cumplimiento de la obligación tributaria y facilitar el financiamiento para la inversión en el desarrollo de su actividad económica. Si bien en su investigación no se contemplan las características particulares de los productores rurales, entre los aspectos generales se resalta la disminución de los costos para formalizarse como propuesta a nivel normativo para los pequeños contribuyentes, con el alivio de requisitos exigidos por los regímenes.

El Instituto de Estudios Estratégicos y Políticas Públicas (IEEPP, 2015) sustenta que uno de los aspectos más costosos es la administración tributaria por la dificultad que representa el control y seguimiento al pago de impuestos de los contribuyentes rurales. Frente a ello, una de las medidas más efectivas consiste en establecer regímenes especiales con tasas bajas y beneficios fiscales. Sin embargo, se presenta el riesgo de que se incorporen grandes grupos económicos para acceder a los beneficios fiscales. Al respecto, se concluye que, en las bolsas agropecuarias, las exenciones en impuestos son aprovechadas por los medianos y grandes productores.

En relación a la sostenibilidad financiera de los productores rurales, Lemos (2015) propone mayores mecanismos fiscales que permitan a los pequeños contribuyentes responder ante una situación de sobreendeudamiento o iliquidez. Específicamente, se propone la simplificación y disminución de la carga fiscal. Más allá de ello, se propone que la norma fiscal reconozca situaciones de dificultades económicas y financieras que retrasan el pago de los impuestos. Lozano (2009) plantea como régimen simplificado para pequeños contribuyentes la implementación de un impuesto plano, con bases gravables amplias y tarifas más bajas, pues permite mayor cumplimiento de los principios tributarios de equidad y eficiencia. Lozano (2014) justifica que este tipo de regímenes ofrece mayores incentivos a las pequeñas y medianas empresas por la baja carga tributaria que representa. Con ello, se puede combatir la informalidad y evasión de manera más eficaz.

En el caso colombiano, la Asociación Bancaria y de Entidades Financieras de Colombia (Asobancaria, 2015) expone algunas recomendaciones que deberían tenerse en cuenta para las futuras reformas tributarias en el país con el objetivo de mejorar las fallas sobre el mercado. Entre ellas, se encuentra el aumento de la informalidad por las debilidades de la política fiscal. Así, se explica que la existencia de dos regímenes para el IVA mejora la simplicidad en su cobro y desincentiva la formalización empresarial. Sin embargo muchos 
prefieren permanecer en un régimen simplificado que represente menor carga fiscal; además, al pasar al régimen común, se pierden todos los beneficios. Por esas razones, se propone un régimen transicional con menores tasas impositivas y posibilidades de inclusión al régimen financiero que constituya un incentivo a la formalización.

La Banco de las Oportunidades (2015a) realizó una investigación que propone las características que debería tener el monotributo como régimen simplificado en Colombia. El principal beneficio del monotributo debe ser la simplicidad que ampare los impuestos nacionales, incluso el IVA, al que se puedan acoger personas físicas y jurídicas, y aquellos que realicen actividades económicas a nivel rural. Al respecto, se propone la desaparición del régimen simplificado del IVA para los contribuyentes que se acojan al monotributo, régimen simplificado que se establece con la Ley 1819 (2016). Hernández (2017) analiza los beneficios que promueve el monotributo en Colombia. El autor resalta como principal beneficio el aporte a la pensión como ahorro para la vejez; además, se encuentra la posibilidad de que los contribuyentes con menores recursos puedan acceder a dicho régimen. Sin embargo, no lo incorpora dentro de los impuestos del IVA, ni realiza un análisis sobre la situación fiscal de los productores rurales. Por el contrario, Bautista (2014) logra evidenciar la complejidad de la estructura tributaria en Colombia en relación con los beneficios fiscales y la poca coherencia en la determinación de estos, pues no son consistentes a lo largo del tiempo.

\subsection{Beneficios fiscales para regímenes simplifica- dos de tributación durante el periodo de 1989- 2020 frente al IVA}

Los regímenes de tributación hacen referencia a las clasificaciones que la norma fiscal realiza sobre los contribuyentes para establecer sus obligaciones tributarias de manera específica o particular frente a sus características socioeconómicas. En el caso de los regímenes simplificados, estos deben tener ciertos criterios que les permitan ser denominados como tales. Dichos criterios tienen que ver con la simplicidad en las obligaciones fiscales, los beneficios que ofrecen a los contribuyentes, y su orientación especial a cobijar sectores económicos que requieren de mayor apoyo estatal para fortalecer su actividad económica, acceder a la formalidad y fortalecer sus procesos estratégicos de mercado en general. En su mayoría, los regímenes simplificados han tenido como principal objetivo disminuir la informalidad, controlar la evasión, y aliviar la carga fiscal a microempresas y pequeños contribuyentes que se encuentran en una posición vulnerable en el mercado; además, han buscado apoyar a las Mipymes en su crecimiento y sostenibilidad financiera.

Como se mencionó, una de las particularidades más importantes de los regímenes simplificados corresponde a las facilidades que se le ofrecen al contribuyente frente a sus obligaciones fiscales de uno o varios impuestos. Específicamente, en el caso del IVA, se encuentra que, desde la compilación del Estatuto Tributario Nacional (2018) con el Decreto 624 de 1989 hasta la Ley 1819 (2016), los pequeños productores y comerciantes de bienes y servicios gravados con el impuesto contaban con el régimen simplificado como mecanismo que les ofrecía como beneficio principal la omisión de la responsabilidad formal y sustancial del impuesto. Por lo tanto, tenían la posibilidad de comercializar un producto de menor valor, lo que les facilitaba la realización de su actividad económica.

De acuerdo con el Estatuto Tributario Nacional (2008, art. 420) y Rojas (2018), el IVA constituye un 
impuesto nacional indirecto, cuyo hecho generador hace referencia a la comercialización de bienes y servicios en el territorio nacional, así como a la importación de bienes muebles que no estén expresamente excluidos por la norma para el caso colombiano. No todos los bienes y servicios que se comercializan en el territorio nacional están gravados con el impuesto ni cuentan con la misma tarifa. En ese sentido, la norma ha establecido beneficios tributarios para quienes producen o comercializan determinados bienes y servicios, tales como la exclusión del gravamen o la tarifa cero. Las dos condiciones asignan responsabilidades y beneficios distintos para los productores y comercializadores. El punto en común es la no responsabilidad sobre el impuesto en la venta de bienes y/o servicios, tal como lo define el Estatuto Tributario Nacional en el caso de los comerciantes de bienes exentos (2008, art. 439).

La exclusión del impuesto sobre los bienes y servicios comercializados en el territorio nacional se encuentra reglamentada en el Estatuto Tributario Nacional (2018, arts. 423-428-2; 476). La medida implica que no se causa el impuesto en la venta o importación. Con las últimas reformas tributarias (Ley 1607, 2012; Ley 1819, 2016; Ley 1943, 2018), se han derogado y modificado varios artículos; así, se ha eliminado la exclusión sobre algunos bienes y servicios. Sin embargo, aún se cuenta con dicho beneficio en gran medida, con lo que se busca promover la inversión en los sectores económicos correspondientes, así como la disminución de los costos en la compra de los bienes que representan, a su vez, insumos en otras actividades económicas que requieren más apoyo para su sostenibilidad económica, tal como el sector agrícola.

Los productores y comercializadores de bienes y servicios excluidos se benefician con este tratamiento al no tener que asumir las responsabilidades formales y sustanciales del impuesto. Esto también termina beneficiando en gran medida a quienes compran los insumos como bienes excluidos, pues se disminuye el costo de forma representativa. En el caso de los que comercializan ese tipo de bienes, es importante resaltar que no tienen derecho a solicitar la devolución por el IVA pagado en la compra de insumos para la prestación del servicio: dicho valor pagado debe sumarse al costo de estos y se puede solicitar como deducción en la declaración de renta.

Por su parte, los bienes exentos del IVA se relacionan con aquellos que están gravados con la tarifa cero (Estatuto Tributario Nacional, 2018, arts. 477-479). Ya que dichos bienes se encuentran gravados, su productor y comercializador recibe el beneficio de contar con derecho a la devolución del mayor valor pagado en los insumos correspondiente al IVA. Sin embargo, en el artículo 481 del Estatuto Tributario Nacional, se establecen los bienes y servicios exentos con derecho a devolución bimestral, entre los cuales se menciona a los productores de los bienes exentos señalados también en el artículo 477 .

Los impuestos descontables hacen referencia al IVA pagado en la adquisición de bienes y servicios, así como en la importación de bienes, tal como lo establece el artículo 485 del Estatuto Tributario Nacional (2018). Ellos pueden dar origen a un saldo a favor, generado en la operación y correspondiente a los excesos en los impuestos descontables sobre el IVA, que puede solicitarse tras haber cumplido con la responsabilidad del impuesto a la renta. El ajuste al valor de dicho impuesto descontable se establece en el artículo 486 del Estatuto Tributario Nacional. Por otro lado, en el artículo 488, se aclara que solo deben descontarse los impuestos sobre las ventas de aquellas operaciones que constituyan costo o gasto en la operación de la actividad económica.

Contabilidad y Negocios (16) 32, 2021 / ISSN 1992-1896 
Frente a la posibilidad de solicitar la devolución generada en saldos a favor, como principal beneficio a productores de bienes exentos, se establece una restricción en el artículo 489 del Estatuto Tributario Nacional (2018), según el cual solo podrán hacerlo los responsables del impuesto sobre las ventas. Con esto, se descarta el beneficio a los comerciantes de bienes exentos (2018, art. 439), es decir, solo los productores pueden favorecerse. Sin embargo, de acuerdo al literal g del artículo 481 del Estatuto Tributario Nacional, deberán adoptar el sistema de facturación electrónica en las transacciones con clientes y proveedores.

De acuerdo a la Ley 1943 (2018), se consideran responsables del IVA a todos aquellos que realicen actividades gravadas, a excepción de pequeños agricultores y ganaderos, entre otros; estos deben cumplir con las condiciones establecidas en el parágrafo 3 del artículo 437 del Estatuto Tributario Nacional, correspondiente a los ingresos, la cantidad de locales, las actividades comerciales desarrolladas, el valor de contratos, el monto de consignaciones y no estar inscrito en el régimen simple de tributación - SIMPLE (establecido por la misma Ley 1943).

Con la Ley 1943 (2018), se establece el régimen simple de tributación que reemplaza el monotributo. Este último fue un régimen simplificado para pequeños contribuyentes establecido por la Ley 1819 (2016), que ofrecía beneficios sobre el IVA, pues cobijaba únicamente el impuesto a la renta; además, se estableció para pequeños comerciantes que cumplieran algunos requisitos básicos. En ese sentido, los pequeños productores del sector agropecuario no fueron tenidos en cuenta. Principalmente, el régimen simple de tributación pretendía simplificar las obligaciones fiscales, reducir la informalidad y disminuir la evasión de pequeños contribuyentes, pero con diferencias sustanciales frente al monotributo. En primer lugar, incluye los impuestos nacionales de renta y consumo, así como un impuesto municipal correspondiente a industria y comercio. En segundo lugar, amplía el universo de sujetos pasivos de forma considerable, con el hecho generador de la obtención de ingresos; por ejemplo, en el caso de los ingresos, se establece un tope máximo de 80.000 de Unidad de Valor Tributario (en adelante, UVT), tanto en el caso de personas jurídicas como de naturales. En otras palabras, los pequeños productores agropecuarios pueden formar parte del régimen simple de tributación.

Los beneficios que ofrece el régimen a sus contribuyentes son la unificación de la obligación tributaria en relación al impuesto a la renta, el impuesto nacional al consumo, el impuesto sobre las ventas y el impuesto de industria y comercio (Estatuto Tributario Nacional, 2018, art. 907). Así, quedan exonerados de la retención en la fuente, es decir, no tienen la obligación de practicar retenciones ni de ser objeto de retenciones, excepto con los pagos laborales y con las retenciones que correspondan al IVA (Estatuto Tributario Nacional, 2018, art. 911).

Los contribuyentes del régimen simple de tributación están obligados a realizar los aportes al sistema general de pensiones de acuerdo con el artículo 903 del Estatuto Tributario Nacional (2018), los cuales pueden ser descontados en las declaraciones bimestrales correspondientes a los anticipos de la contribución anual; a la vez, se podrá descontar en ella dichos anticipos. Otro de los beneficios consiste en el descuento del IVA pagado por medio de tarjetas de crédito y débito, y otros mecanismos electrónicos equivalentes al 0,5\% de los ingresos como base del impuesto, el cual no puede exceder al impuesto a cargo del contribuyente ni a la parte que corresponda al impuesto de industria y comercio (Estatuto Tributario Nacional, 2018, art. 912). 
Los contribuyentes que pertenezcan al régimen simple de tributación no pierden su responsabilidad frente al impuesto sobre las ventas. Para ello, deben tener en cuenta las directrices establecidas en el artículo 915 del Estatuto Tributario Nacional sobre el cumplimiento de su obligación frente al impuesto sobre las ventas. Sin embargo, en el parágrafo del mismo artículo se elimina la posibilidad de solicitar impuestos descontables cuando pertenecen al régimen simple de tributación. Esto desestimularía totalmente la participación de los pequeños productores de bienes exentos en el régimen simple de tributación. En la figura 1, se resumen las posibilidades de acceder al beneficio de la devolución del IVA de acuerdo con el régimen para cada periodo de tiempo.

Figura 1. Caracterización de responsabilidades por tipo de régimen fiscal

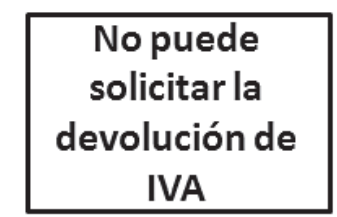

Cumplir obligaciones del impuesto a las Ventas, presentar declaraciones.

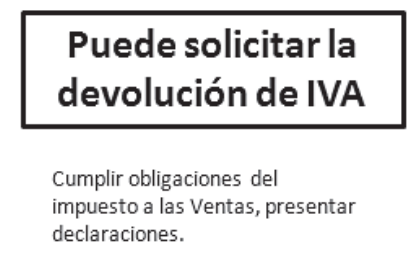

declaraciones.

\section{Responsable del impuesto}

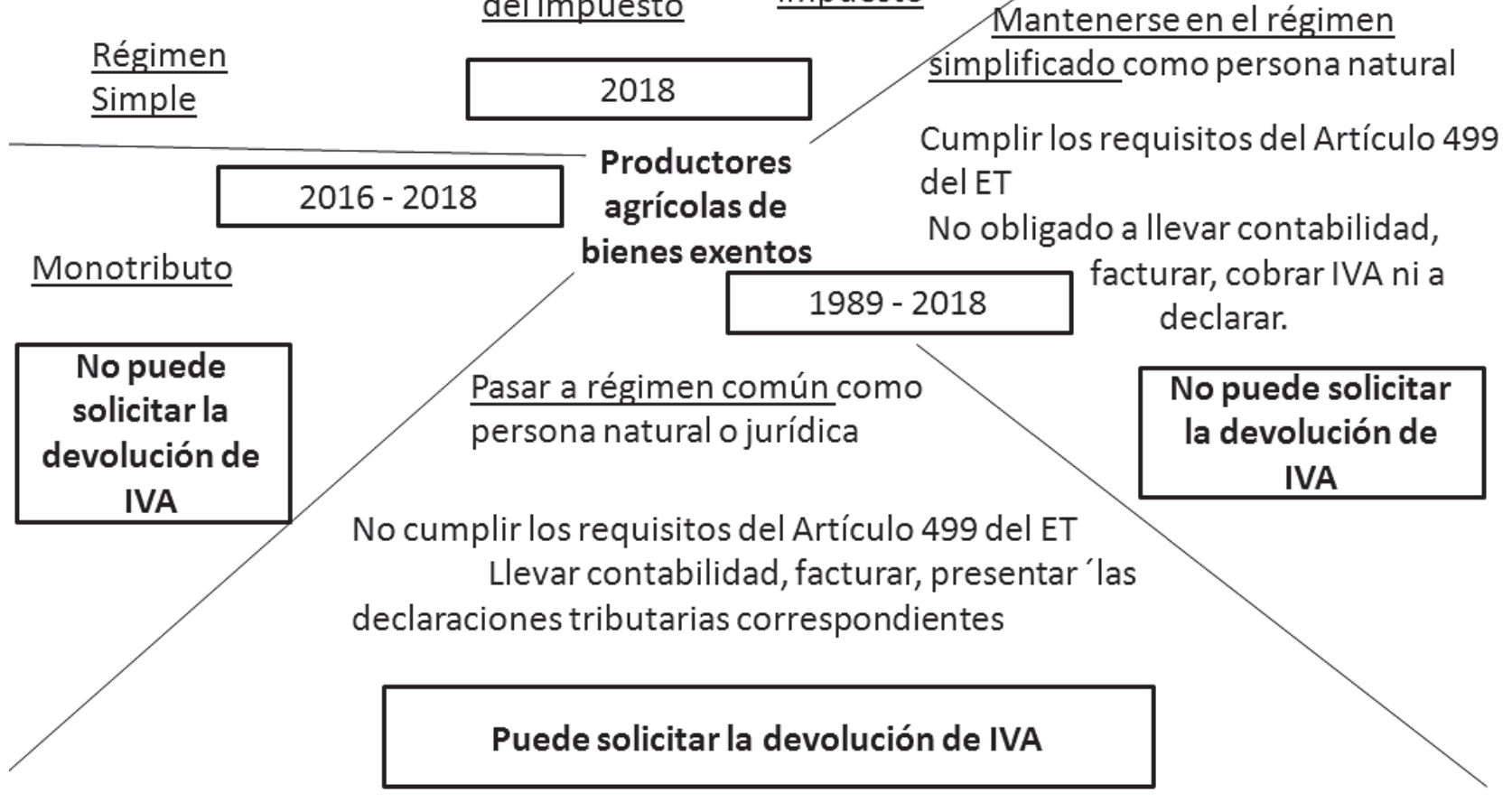

Fuente: Elaboración propia a partir de análisis normativo. 


\subsection{Caracterización económica de pequeños pro- ductores de bienes exentos en Colombia y el norte antioqueño}

El sector agropecuario es uno de los más importantes de la economia colombiana: se caracteriza por una alta diversidad de recursos naturales, que pueden ser explotados de manera sostenible en la produccion de diferentes bienes. Sin embargo, también se trata de un territorio con graves deficiencias que amenazan la sostenibilidad económica de pequeñas y medianas empresas o bien proyectos de emprendimiento, en especial, aquellos liderados por pequeños sectores que se encuentran en una situación económica más vulnerable (Cámara de Comercio del Oriente Antioqueño, 2018). Con el crecimiento poblacional, el aumento de la contaminación y la debilidad de las economías emergentes, se establecen grandes retos para la producción agrícola. Se busca aumentar los niveles de producción respetando la sostenibilidad ambiental con el fin de generar un valor agregado que disminuya el grado de vulnerabilidad frente a las variaciones de precios. Actualmente, Colombia es uno de los países con mayor capacidad para aumentar sus niveles de producción agrícola; ademas, cuenta con alta disponibilidad de tierras para el desarrollo de la agricultura (Villanueva, 2018).

Villanueva (2018) detalla el crecimiento histórico de la producción agropecuaria en Colombia de 2000 a 2016. En el úlitmo año de ese periodo, se alcanzó una producción de 77.378 millones en cuentas nacionales, de acuerdo a las cifras del Departamento Administrativo Nacional de Estadística (DANE, 2018). Dicha cantidad representó el aumento del $14 \%$ con respecto al periodo anterior y un $9,0 \%$ del PIB. En relación al estudio que hace de diferentes fuentes, Villanueva (2018) resalta factores clave relacionados con el sector agrícola, tales como la disponibilidad de tierras, las facilidades en el suministro de agua, y la diversidad topografica y climática. La ganadería de leche se encuentra entre los productos fundamentales para el desarrollo agrícola y cuenta con mayores posibilidades para la generación de empleo. Así mismo, resalta las principales necesidades de dicho sector para el fortalecimiento económico, un mayor uso de tecnologia, un diagnóstico oportuno en patógenos y enfermedades, generación de bioinsumos para mejorar la nutrición de los animales productores y posterior mejoramiento de la calidad de la carne y leche, y aumentos de la producción con tecnologias sustentables. Por lo expuesto, desde el Estado, se busca crear programas que impacten de manera positiva en el desarrollo del sector agrícola. Los últimos proyectos desarrolados en el año 2018 se enfocaron en innovaciones, cierre de brechas tecnológicas y aumento de productividad, entre otros aspectos (Villanueva, 2018).

Frente al estudio del sector lácteo, es importante identificar la cadena de suministro y producción que se genera en la producción lechera y la venta. En primer lugar, los agricultores se ubican como los proveedores de leche, cuya producción diaria les permite tener mayor flujo de caja y liquidez. Por ello, deben ser cuidadosos en la alimentación e higiene de las vacas para el proceso de extracción, pues esto afecta de manera directa el precio del producto. Los productores pueden ser de dos sistemas: únicamente de lechería o de doble propósito. En el último caso, también se comercializa la carne de terneros y ganado en general. De acuerdo al estudio del DANE (2018), la calidad de la producción de leche en el norte ha disminuido por el procentaje de grasas y sólidos totales, especificamente, en los municipios más productores, como Belmira, San José de la Montaña, Santa Rosa de Osos y Toledo, entre otros. Al parecer, el intenso verano afectó la calidad de las pasturas, por lo que se redujo la producción y aumentó el precio. 
Como parte del desarrollo de esta investigación, se realizó un diagnóstico sobre una muestra de la población de pequeños productores de leche en municipios en el altiplano norte de Antioquia: Santa Rosa de Osos, Entrerríos, San Pedro de los Milagros y Belmira. La finalidad consistió en identificar las principales características socioeconómicas de los pequeños productores de leche. Además, se buscó indagar en el conocimiento que tienen los productores con respecto a los beneficios que tienen sobre el IVA por producir un bien exento y los requisitos para aprovechar dicho beneficio, así como la dispocisión para establecer la estructura contable y organizacional para poder acceder a dichos beneficios. El trabajo de campo se realizó en el marco del proyecto de investigación "Medición de la solicitud de devolución de IVA en las pymes del sector lechero en la zona altiplano norte de Antioquia”, a partir del convenio entre la Corporación Universitaria Remington y la Universidad Católica Luis Amigó. La encuesta se aplicó a una población de cien pequeños productores en los municipios de Santa Rosa de Osos, Entrerríos, San Pedro de los Milagros y Belmira.

A partir de la encuesta realizada, entre los datos socieconómicos, se encontró que la mayoría de la población productora corresponde a hombres $(83,75 \%)$ mayores de 40 ańos (65\%). Como se muestra en las figuras 2 y 3 , cuentan con bajos niveles de estudios: alrededor del $82 \%$ tiene estudios de primaria o secudaria. Además, en la mayoría de casos ( $92 \%$ de los encuestados), la actividad de producción lechera se desarrolla como actividad de cuenta propia o bajo la propia responsabilidad frente a los riesgos implicados. Por otra parte, en las figuras 4 y 5 , se evidencia que los producores lecheros constituyen una población con mayores niveles de vulnerabilidad en comparación a otros sectores frente a los riesgos del mercado por las deficiencias en educación, la poca organización y capacidad económica.

Figura 2. Caracterización de nivel estudios

\section{Nivel de estudios}

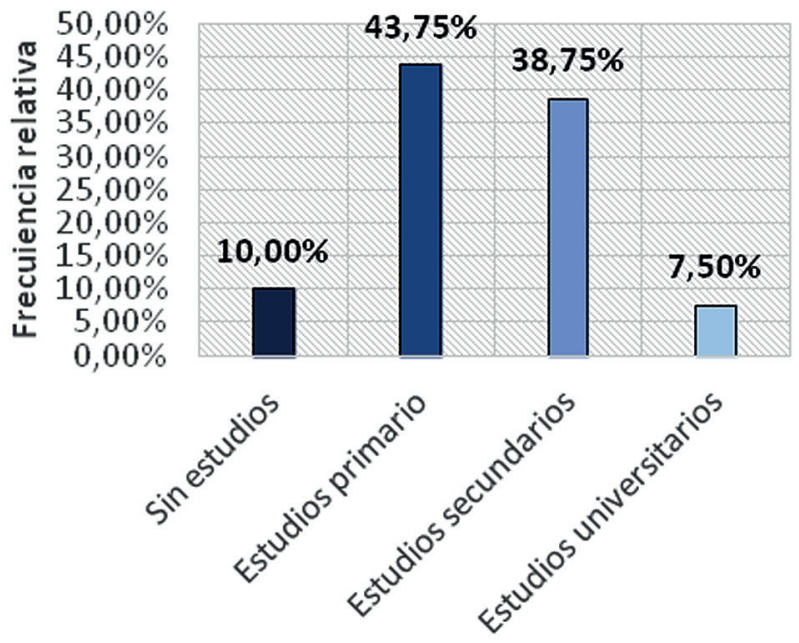

Nota. La figura 2 muestra los resultados obtenidos en la aplicación de la encuesta a pequeńos productores en Belmira (Antioquia) en el marco del proyecto.

Figura 3. Caracterización laboral

\section{Situación laboral}

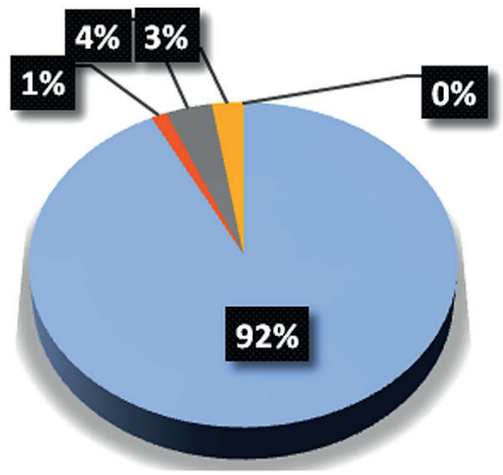

- Trabajador por cuenta propia

- Trabajador por cuenta ajena

- Jubilado/Retirad o

- Trabajo en compañía

- Subcontratación

Nota. La figura 3 muestra los resultados obtenidos en la aplicación de la encuesta a pequeńos productores en Belmira (Antioquia) en el marco del proyecto. 
Figura 4. Caracterización de gestión administrativa

\section{LLEVA CONTABILIDAD DE LA ACTIVIDAD LECHERA}

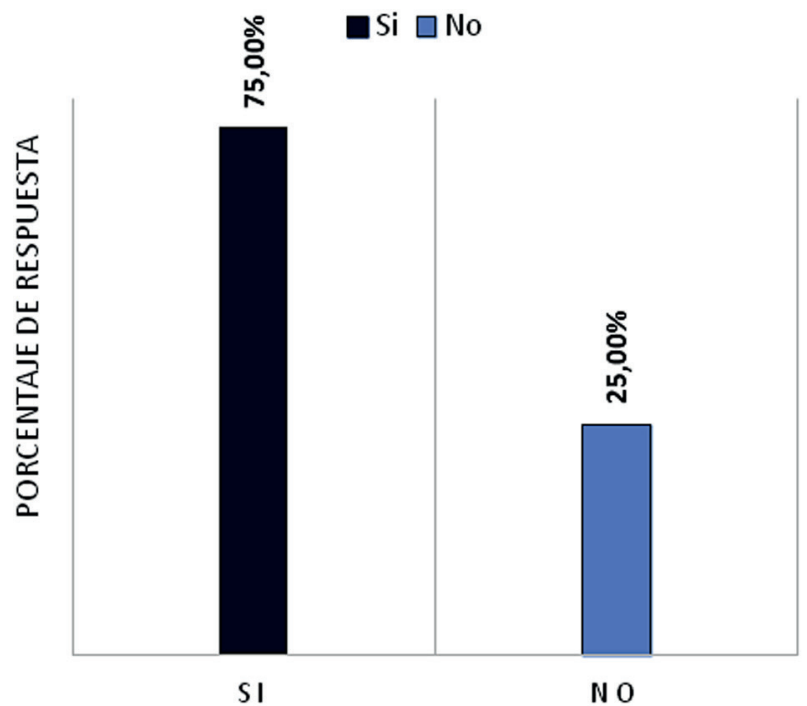

Nota. La figura 4 muestra los resultados obtenidos en la aplicación de la encuesta a pequeños productores en Belmira (Antioquia) en el marco del proyecto.

Con respecto a la producción de leche, San Pedro de los Milagros cuenta con el nivel más alto en producción, seguido de Santa Rosa de Osos, con el 40\% y $25 \%$ respectivamente. El $100 \%$ de los encuestados pertenece a una cooperativa lechera que les facilita la comercialización del producto y los protege en alguna medida de las variaciones de precios. Además, como puede observarse en las figuras 6 y 7 , el $68 \%$ de los encuestados desarrollan la actividad con una antigüedad superior a los seis años. La estabilidad en el sector constituye un aspecto positivo, pues permite afianzar los conocimientos e introducir nuevas tecnologías y procesos a favor de la productividad y sostenibilidad de la actividad.
Figura 5. Caracterización de percepción fiscal

\section{Reconocer el impuesto del IVA como un valor agregado en las compras de insumo}

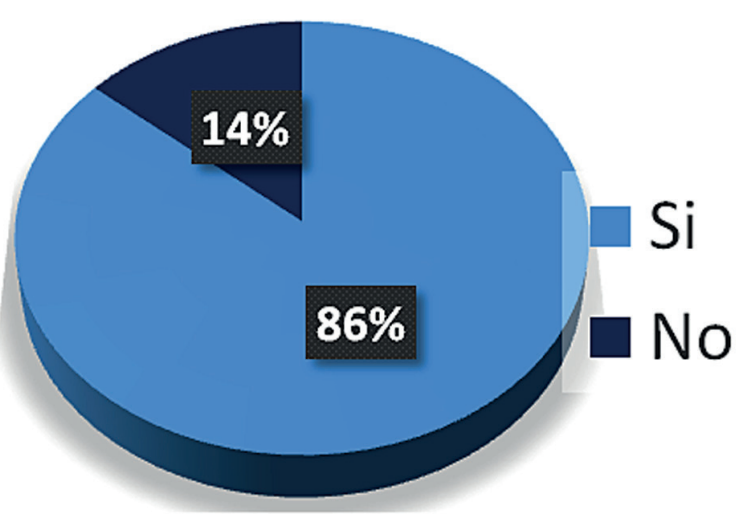

Nota. La figura 5 muestra los resultados obtenidos en la aplicación de la encuesta a pequeños productores en Belmira (Antioquia) en el marco del proyecto.

Figura 6. Caracterización de pequeños productores: genero

\section{TOTAL DE ENCUESTADOS POR SEXO}

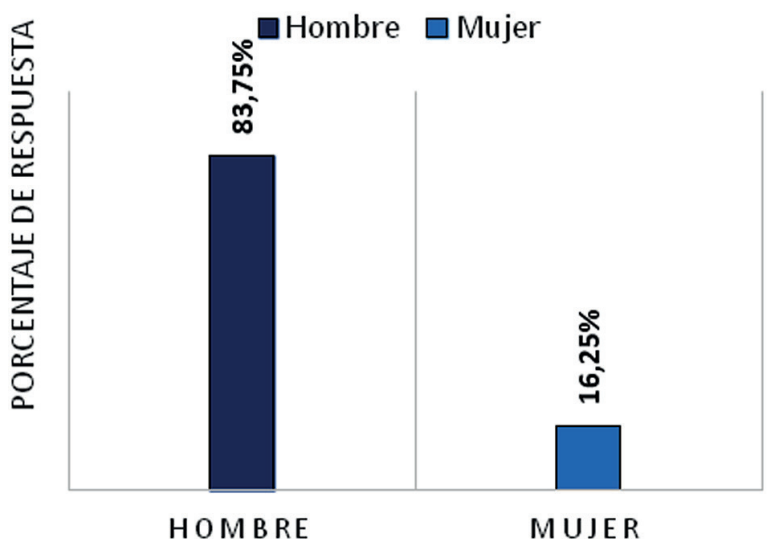

Nota. La figura 6 muestra los resultados obtenidos en la aplicación de la encuesta a pequeños productores en Belmira (Antioquia) en el marco del proyecto. 
Figura 7. Caracterización de pequeńos productores: edad

\section{Edad}

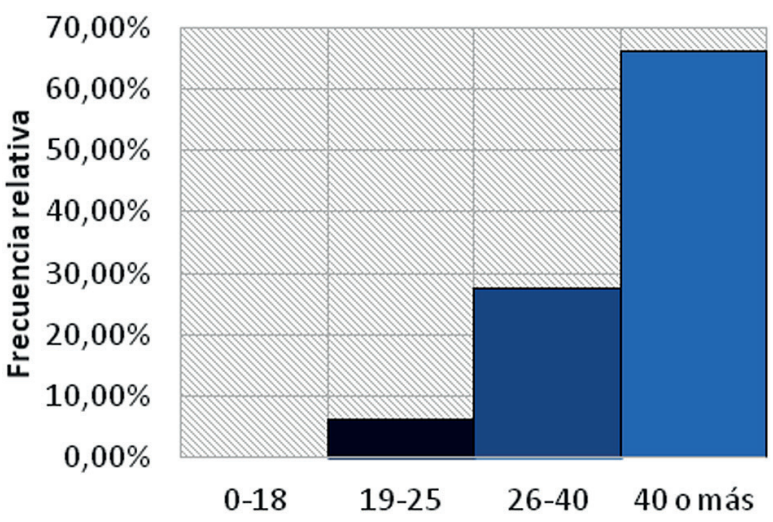

\section{$\square$ 0-18 $\square 19-25 \quad \square 26-40 \quad \square 40$ omás}

Nota. La figura 7 muestra los resultados obtenidos en la aplicación de la encuesta a pequeńos productores en Belmira (Antioquia) en el marco del proyecto.

Como se evidencia en las figuras 8 y 9 , el $55 \%$ de los encuestados pertenecían al régimen simplificado de IVA, comparado con el 45\% del régimen común. Del total de productores correspondientes al régimen simplificado, solo el 11\% manifiesta disposición de pasar al régimen común. Esto evidencia una percepción negativa frente a dicho régimen y a la carga fiscal de los contribuyentes adscritos al mismo.

En relación a la organización de los procesos contables, en las figuras 10 y 11 , se evidencia que el $75 \%$ de encuestados sí llevan contabilidad y el 86\% de los encuestados reconocen el costo que asumen en las compras de insumos por el IVA pagado. Esto indica que, pese a la percepción negativa sobre el cambio de régimen, los productores pueden recibir una orientación adecuada que les permita beneficiarse de las ventajas como productores de bienes exentos en materia fiscal.
Figura 8. Caracterización de ubicación de pequeńos productores

\section{Municipio}

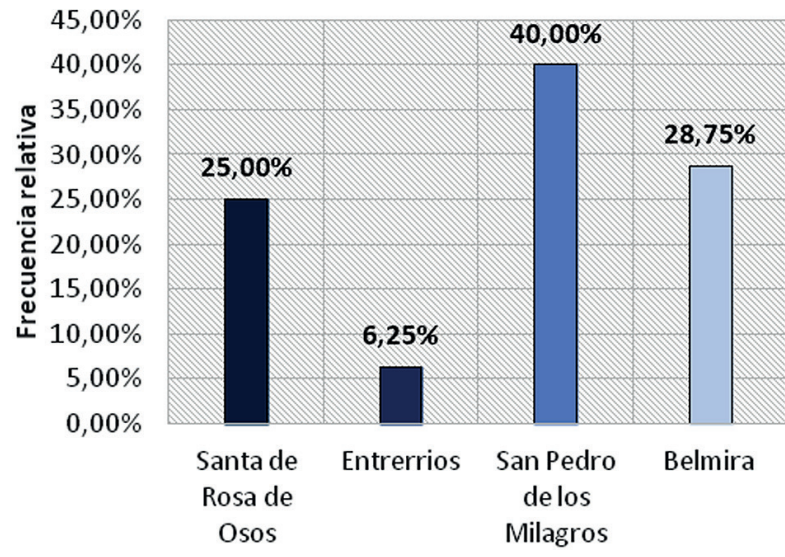

Nota. La figura 8 muestra los resultados obtenidos en la aplicación de la encuesta a pequeńos productores en Belmira (Antioquia) en el marco del proyecto.

Figura 9. Antigüiedad en actividad económica

\section{Antigüedad en años}

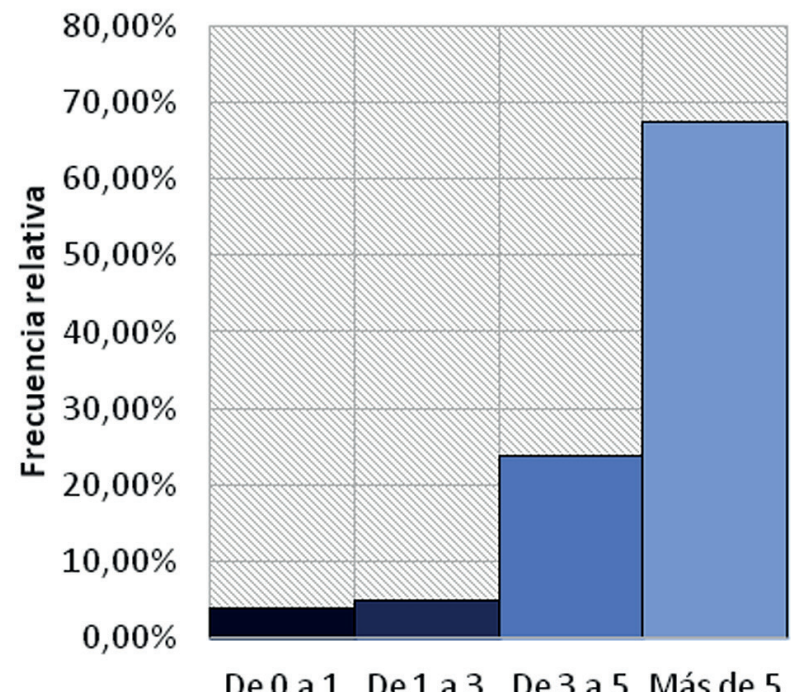

Nota. La figura 9 muestra los resultados obtenidos en la aplicación de la encuesta a pequeños productores en Belmira (Antioquia) en el marco del proyecto. 
Figura 10. Caracterización de incorporación a regímenes

\section{Regimen al que pertenece}

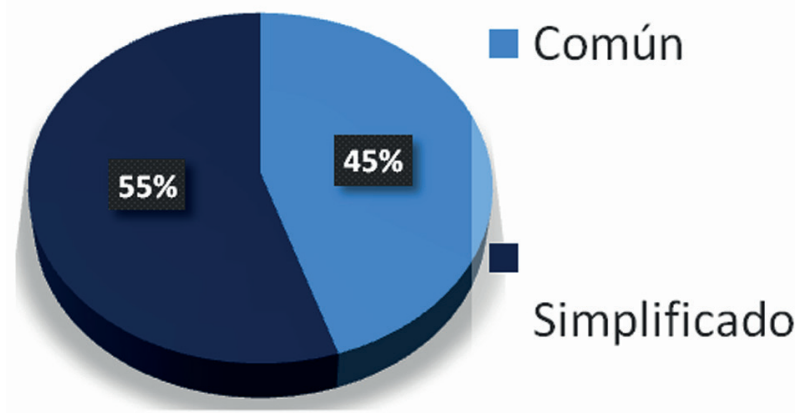

Nota. La figura 10 muestra los resultados obtenidos en la aplicación de la encuesta a pequeńos productores en Belmira (Antioquia) en el marco del proyecto.

Figura 11. Disposición para pertenecer a régimen de responsabilidad del impuesto

\section{Si perternece al regimén simplificado, disposición de} pasar al regimén común

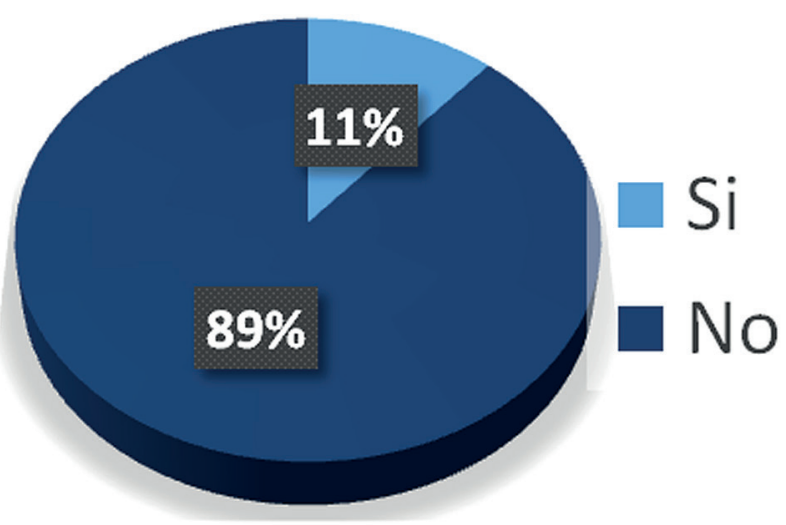

Nota. La figura 11 muestra los resultados obtenidos en la aplicación de la encuesta a pequeńos productores en Belmira (Antioquia) en el marco del proyecto.

\section{Resultados}

\subsection{Analisis comparativo de los beneficios fiscales por regímenes de tributación}

En la figura 12, se resume el análisis normativo en función de los beneficios fiscales frente al IVA para los productores de bienes exentos. De acuerdo con el estudio realizado, se puede identificar fácilmente que solo el régimen simplificado y el régimen común han ofrecido algún tipo de beneficio a los pequeños productores agrícolas, pero dichos beneficios son totalmente opuestos y mutuamente excluyentes. Al ser productores de bienes exentos, a los productores agrícolas del sector lechero estudiado les favorece mantener la calidad de responsables del impuesto, pues eso les permite poder descontar el IVA pagado como mayor valor en la compra de insumos que forman parte de sus costos y gastos.

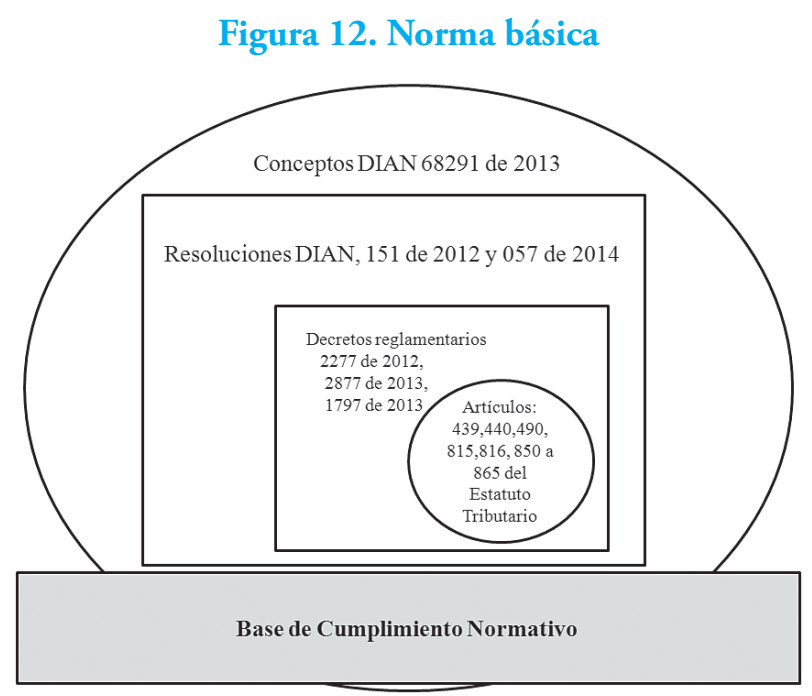

Nota. La figura 12 detalla las bases normativas a nivel tributario para productores de leche.

Como resultado, se define una ruta metodológica en la figura 13 para los pequeños productores de los bienes exentos, específicamente, en la producción de leche. 
Así, se plantea que puedan aplicar a uno de los mayores beneficios como productores de bienes exentos, que corresponde a la posibilidad de solicitar la devolución del mayor valor pagado en sus costos y gastos por concepto del IVA. Para ello, en primer lugar, se deben implementar procesos contables y administrativos que les permitan registrar la información financiera correspondiente al desarrollo de la actividad económica, y llevar un control de los documentos como soportes de las transacciones realizadas con proveedores y clientes. Después de haber logrado dicho nivel de organización, se debe verificar el cumplimiento de los requisitos para poder ser catalogados como "responsables del impuesto" bajo la norma actual. Posteriormente, se debe iniciar el proceso de implementación de la facturación electrónica en las transacciones con proveedores y clientes; además, se debe establecer el proceso tributario de declaración del impuesto sobre las ventas, la declaración de impuesto a la renta y la posterior solicitud de la devolución del impuesto.

\section{Figura 13. Recomendaciones de gestión contable} tributaria

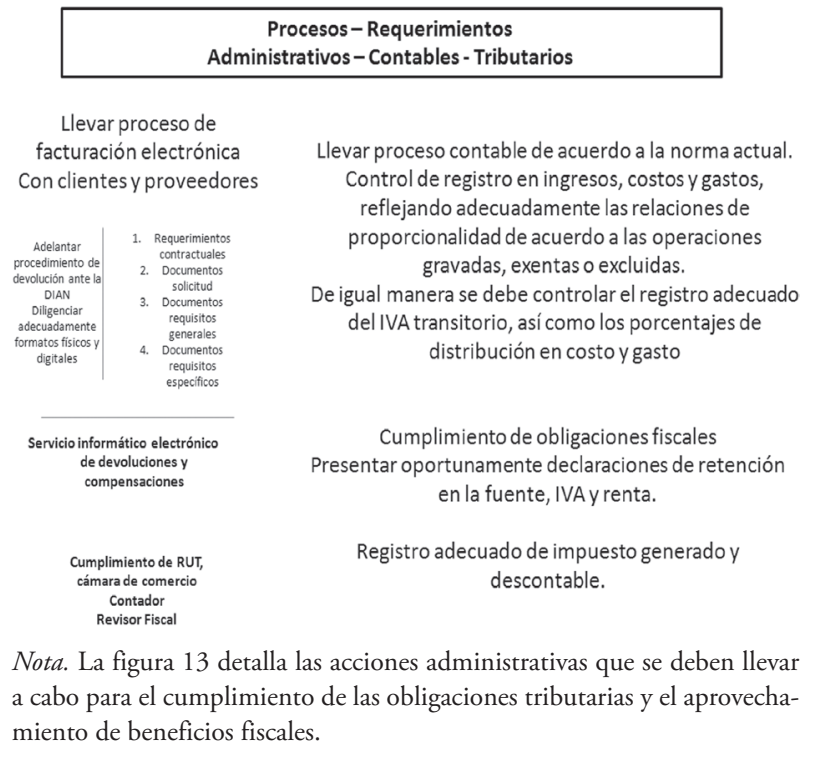

\subsection{Análisis comparativo de beneficios fiscales a partir de la carga fiscal}

Tras haber analizado las condiciones normativas que reglamentan las obligaciones fiscales de los productores de leche y los beneficios fiscales en relación al IVA, se procede a monetizar la carga fiscal y el beneficio del IVA descontable a partir de un ejemplo numérico, el cual se construyó sobre la base de los datos sobre costos y precios para productores de leche en el territorio antioqueño de acuerdo a la Federación Colombiana de Ganaderos (FEDEGAN, 2016) y a datos recopilados de los productores encuestados en los municipios del altiplano norte de Antioquia. Así, se determinó un precio promedio de 1.100 por litro de leche, con una participación del costo sobre los ingresos de $50 \%$ en alimentación para el ganado, $16 \%$ para fertilizantes, $13 \%$ para pagar la nómina, 3\% para medicamentos, $6 \%$ para materiales y $10 \%$ para gastos en general. De acuerdo con ello, se proyectan dos escenarios: el de un productor no responsable del impuesto con ingresos menores a 3.500 de UVT y el de un productor responsable bajo el régimen común con tres alternativas de ingreso que se repiten en el escenario del régimen simple de tributación (ver tabla 1 ).

El objetivo de proyectar diferentes rangos de ingreso consiste, en principio, en diferenciar y analizar de forma comparativa los ingresos y costos de productores que, al estar en el mismo régimen, soportan una incidencia distinta de la carga fiscal. Así, se busca determinar cómo sería dicha incidencia monetizada si estuviese en otro régimen. Por ello, en los rangos se toman en cuenta los montos mínimos y máximos para los responsables del impuesto (régimen común) o el régimen simple de tributación. 
Tabla 1. Comparación de carga fiscal por el tipo de régimen fiscal

\begin{tabular}{|c|c|c|c|c|c|c|c|c|}
\hline & $\begin{array}{l}\text { Régimen sim- } \\
\text { plificado / no } \\
\text { responsables }\end{array}$ & \multicolumn{3}{|c|}{ Régimen común / responsable de impuesto } & \multicolumn{4}{|c|}{ Régimen simple de tributación } \\
\hline & $\begin{array}{c}\text { Estatuto Tribu- } \\
\text { tario Nacional } \\
\text { (art. 437, par. 3) }\end{array}$ & & & & & & & \\
\hline & $\begin{array}{c}\text { Tope de } \\
\text { ingresos de } \\
3.500 \text { de UVT } \\
(\$ 119.945 .000)\end{array}$ & $\begin{array}{c}\text { Ingresos } \\
\text { superiores a } \\
3.500 \text { de UVT } \\
(\$ 119.945 .000)\end{array}$ & $\begin{array}{c}\text { Ingresos de } \\
3.500 \text { de } \\
\text { UVT }>x<40.000 \\
\text { de UVT }\end{array}$ & $\begin{array}{c}\text { Ingresos de } \\
40.000 \text { de } \\
\text { UVT }>\mathrm{x}<80.000 \\
\text { de UVT }\end{array}$ & $\begin{array}{c}\text { Tope de } \\
\text { ingresos de } \\
3.500 \text { de UVT } \\
(\$ 119.945 .00)\end{array}$ & $\begin{array}{c}\text { Ingresos } \\
\text { superiores a } \\
3.500 \text { de UVT } \\
(\$ 119.945 .000)\end{array}$ & $\begin{array}{c}\text { Ingresos de } \\
3.500 \text { de } \\
\text { UVT }>\mathrm{x}<40.000 \\
\text { de UVT }\end{array}$ & $\begin{array}{c}\text { Ingresos de } \\
40.000 \text { de } \\
\text { UVT }>x<80.000 \\
\text { de UVT }\end{array}$ \\
\hline \multicolumn{9}{|c|}{ Ingresos operacionales } \\
\hline $\begin{array}{l}\text { Ventas de } \\
\text { producto }\end{array}$ & 99.000 .000 & 132.321 .600 & 1.386 .000 .000 & 2.376 .000 .000 & 99.000 .000 & 132.321 .600 & 1.386 .000 .000 & 2.376 .000 .000 \\
\hline $\begin{array}{l}\text { Menos: costo } \\
\text { de venta }\end{array}$ & 63.360 .000 & 84.685 .824 & 887.040 .000 & 1.520 .640 .000 & 63.360 .000 & 84.685 .824 & 887.040 .000 & 1.520 .640 .000 \\
\hline $\begin{array}{l}\text { Alimentos } \\
\text { para el } \\
\text { ganado }\end{array}$ & 36.000 .000 & 48.116 .945 & 504.000 .00 & 864.000 .000 & 36.000 .000 & 48.116 .945 & 504.000 .00 & 864.000 .000 \\
\hline Fertilizantes & 11.520 .000 & 15.397 .423 & 161.280 .000 & 276.480 .000 & 11.520 .000 & 15.397 .423 & 161.280 .000 & 276.480 .000 \\
\hline $\begin{array}{l}\text { Pago de } \\
\text { nómina }\end{array}$ & 9.360 .000 & 12.510 .406 & 131.040 .000 & 224.640 .000 & 9.360 .000 & 12.510 .406 & 131.040 .000 & 224.640 .000 \\
\hline $\begin{array}{l}\text { Medicamen- } \\
\text { tos }\end{array}$ & 2.160 .000 & 2.887 .017 & 30.240 .000 & 51.840 .000 & 2.160 .000 & 2.887 .017 & 30.240 .000 & 51.840 .000 \\
\hline Materiales & 4.320 .000 & 5.774 .033 & 60.480 .000 & 103.680 .000 & 4.320 .000 & 5.774 .033 & 60.480 .000 & 103.680 .000 \\
\hline $\begin{array}{l}\text { Utilidad } \\
\text { bruta }\end{array}$ & 35.640 .000 & 47.635 .776 & 498.960 .00 & 855.360 .000 & 35.640 .000 & 47.635 .776 & 498.960 .00 & 855.360 .000 \\
\hline $\begin{array}{l}\text { Menos: gastos } \\
\text { operacionales }\end{array}$ & 10.263 .671 & 13.683 .143 & 108.864 .000 & 186.624 .000 & 10.263 .671 & 13.683 .143 & 108.864 .000 & 186.624 .000 \\
\hline $\begin{array}{l}\text { Servicios } \\
\text { públicos }\end{array}$ & 720.000 & 962.339 & 10.080 .000 & 17.280 .000 & 720.000 & 962.339 & 10.080 .000 & 17.280 .000 \\
\hline $\begin{array}{l}\text { Impuesto } \\
\text { predial }\end{array}$ & 576.000 & 769.871 & 8.064 .000 & 13.824 .000 & 576.000 & 769.871 & 8.064 .000 & 13.824 .000 \\
\hline Aseo & 1.080 .000 & 1.443 .508 & 15.120 .000 & 25.920 .000 & 1.080 .000 & 1.443 .508 & 15.120 .000 & 25.920 .000 \\
\hline $\begin{array}{l}\text { Manteni- } \\
\text { miento }\end{array}$ & 1.440 .000 & 1.924 .678 & 20.160 .000 & 34.560 .000 & 1.440 .000 & 1.924 .678 & 20.160 .000 & 34.560 .000 \\
\hline Otros & 4.641 .004 & 6.616 .080 & 55.440 .000 & 95.040 .000 & 4.641 .004 & 6.616 .080 & 55.440 .000 & 95.040 .000 \\
\hline $\begin{array}{l}\text { Depreciacio- } \\
\text { nes }\end{array}$ & 1.806 .667 & 1.966 .667 & 18.066 .667 & 29.006 .667 & 1.806 .667 & 1.966 .667 & 18.066 .667 & 29.006 .667 \\
\hline $\begin{array}{l}\text { Utilidad } \\
\text { operacional }\end{array}$ & 25.376 .329 & 33.952 .633 & 480.893 .333 & 668.736 .000 & 25.376 .329 & 33.952 .633 & 480.893 .333 & 668.736 .000 \\
\hline
\end{tabular}

Fuente: Elaboración propia a partir de datos obtenidos de productores Belmira en el marco del proyecto de investigación. 
En la tabla 2, se pueden evidenciar las diferencias en la incidencia del impuesto a la renta por tipo de régimen. Esto, sumado al beneficio en la devolución del IVA, permite identificar cómo el régimen simple de tributación incluye a productores de leche que dejarían de ser pequeños contribuyentes debido a sus ingresos. Además, se puede observar de qué manera dicho régimen logra una menor incidencia de la carga fiscal para los contribuyentes con respecto al régimen de responsabilidad frente al IVA, conocido antes de la Ley 1943 de 2018 como "régimen común". Así, incluso el beneficio de devolución del IVA deja de ser representativo frente a un impuesto a la renta significativamente menor cuando aumenta el volumen de ingresos, en oposición a una situación con ingresos menores a 40.000 de UVT.

Tabla 2. Comparación de carga fiscal de acuerdo con el régimen de tributación

\begin{tabular}{|c|c|c|c|c|c|c|c|c|}
\hline & $\begin{array}{l}\text { Régimen sim- } \\
\text { plificado / no } \\
\text { responsables } \\
\text { del impuesto }\end{array}$ & \multicolumn{3}{|c|}{ Régimen común responsable del impuesto } & \multicolumn{4}{|c|}{ Régimen simple de tributación } \\
\hline & & \multicolumn{3}{|c|}{ Obligaciones fiscales } & \multirow[b]{2}{*}{ (a) } & \multirow[b]{2}{*}{ (b) } & \multirow[b]{2}{*}{ (c) } & \multirow[b]{2}{*}{ (d) } \\
\hline Renta & (a) & (b) & (c) & (d) & & & & \\
\hline Ingresos brutos & 99.000 .000 & 132.321 .6000 & 1.386 .000 .000 & 2.376.000.000 & & & & \\
\hline \multicolumn{9}{|c|}{ Ingresos no constitutivos de renta } \\
\hline Costos y gastos procedentes & 63.360 .000 & 84.685 .824 & 887.040 .000 & 1.520 .640 .000 & & & & \\
\hline Renta líquida & 35.640 .000 & 47.635 .776 & 498.960 .000 & 855.360 .000 & & & & \\
\hline $10 \%$ renta líquida & 3.564 .000 & 4.763 .578 & 49.896 .000 & 85.536 .000 & & & & \\
\hline \multicolumn{9}{|l|}{ Rentas exentas y deducciones } \\
\hline $\begin{array}{l}\text { Límite en rentas exentas y } \\
\text { deducciones }\end{array}$ & 3.564 .000 & 4.763 .578 & 49.896 .000 & 85.536 .000 & & & & \\
\hline Renta líquida cedular & 32.076 .000 & 42.872 .198 & 449.064 .000 & 769.824 .00 & & & & \\
\hline UVT & 901 & 1.204 & 12.612 & 21.620 & & & & \\
\hline Impuesto & - & 771.508 & 112.919 .400 & 202.732 .200 & & & & \\
\hline \multicolumn{9}{|l|}{ Declaración IVA } \\
\hline Solicitud de devolución & 2.534 .400 & 3.387 .433 & 35.481 .600 & 60.825 .600 & & & & \\
\hline \multicolumn{9}{|l|}{ Declaración simple } \\
\hline Ingresos brutos & & & & & 99.000 .000 & 132.321 .600 & 1.386 .000 .000 & 2.376 .000 .000 \\
\hline Base en UVT & & & & & 2.780 & 3.716 & 38.925 & 66.728 \\
\hline Anticipo SIMPLE & & & & & 2.178 .000 & 2.911 .075 & 30.492 .000 & 52.272 .000 \\
\hline $\begin{array}{l}\text { Aportes a pensión a cargo } \\
\text { de empleador }\end{array}$ & & & & & 1.123 .200 & 1.501 .249 & 15.724 .800 & 26.956 .800 \\
\hline Anticipo SIMPLE & & & & & 1.054 .800 & 1.409 .826 & 14.767 .200 & 25.315 .200 \\
\hline Costa IVA asumido & & & & & 2.534 .400 & 3.387 .433 & 35.481 .600 & 60.825 .600 \\
\hline Total de carga fiscal & -2.534 .400 & -2.615 .925 & 77.437 .800 & 141.906 .600 & 3.589 .200 & 4.707 .259 & 50.248 .800 & 86.140 .800 \\
\hline
\end{tabular}




\section{Conclusiones y recomendaciones}

A pesar de los recurrentes cambios que se han realizado sobre la estructura tributaria en Colombia, poco se ha avanzado en la implementación de un régimen simplificado para pequeños contribuyentes del sector agrícola que les otorgue beneficios sustanciales en la disminución de la carga fiscal. Al ser productores de bienes exentos, el beneficio más representativo para los pequeños productores del sector lechero corresponde a la posibilidad de solicitar la devolución del mayor valor pagado por impuesto sobre las ventas en operaciones de costos y gastos. El beneficio de solicitud de devolución sobre el IVA únicamente se ha contemplado para los contribuyentes pertenecientes al régimen común, que pasan a ser catalogados como responsables del impuesto luego de la reforma de la Ley 1943 de 2018.

Frente a la situación estudiada, los pequeños productores de leche deben fortalecer sus procesos contables para tener una estructura organizada para inscribirse en el RUT (Registro Único Tributario) como contribuyentes del impuesto. Además, deben implementar el proceso de facturación electrónica, y presentar declaraciones tributarias y solicitar la devolución del impuesto. Por ello, se requieren mayores procesos de acompañamiento, asesoría y capacitación a los pequeños productores del sector agrícola, pues constituyen una población con bajos conocimientos técnicos, debilidades en procesos contables y administrativos, y gran vulnerabilidad económica frente a las exigencias del mercado. Con dichos apoyos, podrán aprovechar los beneficios de las normas fiscales, y estas no se convertirán en un obstáculo para su crecimiento y sostenibilidad financiera.

A partir de las conclusiones de la investigación, se recomienda la formalización a los productores de leche.
Además, se propone que cuenten con procedimientos contables y tributarios de buena calidad. Así, podrán tener control financiero de la información y los resultados de la actividad; mejor planeación estratégica como un agregado de dicha tarea; y pasar al régimen simple de tributación, con el fin de aprovechar la disminución en la carga fiscal del impuesto a la renta en beneficio del crecimiento económico de su actividad a partir de mayores inversiones.

\section{Referencias}

Arroyo, I. (2013). Régimen Tributario Costarricense: Marco General y Principios tributarios. Derecho en Sociedad. Revista Electrónica Facultad de Derecho ULACIT, (4), 3-52. Recuperado de https://www.researchgate.net/ publication/279516716_Regimen_Tributario_Costarricense_Marco_General_y_Principales_Tributos p:// www.ulacit.ac.cr/files/revista/articulos/esp/resumen/67_ jenifferarroyo.pdf [Consulta:18 de enero de 2019].

Asociación Bancaria y de Entidades Financieras de Colombia (Asobancaria). (2015, 11 de mayo). Hacia un régimen tributario transicional. Semana Económica. Recuperado de https:/www.asobancaria.com/wpcontent/uploads/2018/02/Sem_994.pdf [Consulta: 18 de enero de 2019].

Banca de las Oportunidades. (2015a). Propuesta para el diseño e implementación del monotributo en Colombia (versión ajustada con comentarios de entidades de Gobierno). Recuperado de http://bancadelasoportunidades.gov. co/sites/default/files/2017-01/monotributo.pdf [Consulta: 18 de enero de 2019].

Banca de las Oportunidades (2015b). Reporte de inclusión financiera. Bogotá: Superintendencia Financiera de Colombia. https://bancadelasoportunidades.gov.co/ sites/default/files/2017-03/RIF-2015_2.pdf [Consulta: 18 de enero de 2019].

Banco Interamericano de Desarrollo. (2006). Regímenes especiales de tributación para pequeños contribuyentes 
en América Latina. Recuperado de https://www.cepal. org/ilpes/noticias/paginas/2/27472/Dario\%20Gonzalez\%20Fiscalidad\%20de\%20la\%20PYME\%20 en\%20AL.pdf [Consulta: 18 de enero de 2019].

Bautista, J. (2014). Los beneficios tributarios en el impuesto de renta: análisis de sus determinantes técnicos y su impacto fiscal (Documento para Justicia Tributaria en Colombia). Recuperado de https://www.justiciatributaria. co/wp-content/uploads/2014/10/DOCUMENTOFINAL-ANALISIS-BENEFICIOS-TRIBUTARIOSIMPUESTO-DE-RENTA.pdf [Consulta: 18 de enero de 2019].

Cámara de Comercio Oriente Antioqueńo (2018). Concepto económico del Oriente Antioqueño. Recuperado de https://www.ccoa.org.co/Portals/0/Biblioteca\%20 virtual/Publicaciones\%20regionales/2018/Concepto \%20econ $\%$ C3\%B3mico\%202018.pdf?ver $=2019$ 02-01-105326-537 [Consulta: 18 de enero de 2019].

Casella, M. (2008, 24-25 de noviembre). Análisis constitucional de los regímenes de tributación [Presentación en conferencia]. Decimoterceras jornadas "Investigaciones en la Facultad" de Ciencias Económicas y Estadística, Rosario, Argentina. Recuperado de https:// rephip.unr.edu.ar/bitstream/handle/2133/7745/ Casella_M\%20E\%20_\%20analisis\%20constitucional $\% 20$ de $\% 20$ los $\% 20$ regimenes\%20de\%20tributacion $\% 20$ simplificados.pdf? sequence $=3$ \&isAllowed $=y$ [Consulta: 18 de enero de 2019].

Chávez A., Peña, C., \& Hernández, M. (2015). Impacto de la reforma fiscal en las microempresas. Revista Global de Negocios, 3(2) 1-12. Recuperado de ftp://ftp.repec.org/ opt/ReDIF/RePEc/ibf/rgnego/rgn-v3n2-2015/RGNV3N2-2015-1.pdf [Consulta: 18 de enero de 2019].

Congreso de Colombia (2012, 26 de diciembre). Ley por la cual se Expiden Normas en Materia Tributaria y se Dictan otras Disposiciones. [Ley N ${ }^{\circ} 1607$ ]. Recuperado de https://colaboracion.dnp.gov.co/CDT/Normograma/ Ley\%201607\%20de\%202012.pdf [Consulta: 18 de enero de 2019].
Congreso de Colombia. (2016, 29 de diciembre). Ley por medio de la cual se Adopta una Reforma Tributaria Estructural, se Fortalecen los Mecanismos para la Lucha contra la Evasión y la Elusión Fiscal, y se Dictan otras Disposiciones (Ley $\mathrm{N}^{\circ}$ 1819). Recuperado de http:// es.presidencia.gov.co/normativa/normativa/LEY\%20 1819\%20DEL\%2029\%20DE\%20DICIEMBRE\%20 DE\%202016.pdf [Consulta: 18 de enero de 2019].

Congreso de Colombia. (2018, 28 de diciembre). Ley por la cual se Expiden Normas de Financiamiento para el Restablecimiento del Equilibrio del Presupuesto General y se Dictan otras Disposiciones [Ley No 1943]. Recuperado de https://cijuf.org.co/sites/cijuf.org.co/files/normativi$\mathrm{dad} / 2018 / \mathrm{LEY} \% 201943 \% 20 \mathrm{DEL} \% 2028 \% 20 \mathrm{DE} \% 20$ DICIEMBRE\%20DE\%202018\%20\%281\%29\%20 \%281\%29.pdf [Consulta: 18 de enero de 2019].

Departamento Administrativo Nacional de Estadística (DANE). (2018). Leche cruda en finca [Boletín]. Recuperado de https://www.dane.gov.co/files/investigaciones/agropecuario/sipsa/BolSipsaLeche_feb_2018.pdf [Consulta: 18 de enero de 2019].

Departamento Administrativo Nacional de la Economía Solidaria (Dansocial). (2008). Análisis de la política fiscal en el sector solidario colombiano. Bogotá: Cootradian. Recuperado de https://www.orgsolidarias.gov. co/sites/default/files/archivos/An\%C3\%A1lisis\%20 de\%20la $\% 20$ pol\%C3\%ADtica $\% 20$ fiscal $\% 20$ en $\% 20$ el\%20sector\%20solidario.pdf [Consulta: 18 de enero de 2019].

Engel, E. (2003). Impuestos y distribución del ingreso en Chile: ¿Es regresivo el IVA? El Trimestre Económico, 70 (280), 745-790. Recuperado de https://search-proquest-com.ezproxy.uniminuto.edu/docview/74866963 3 ?accountid=48797 [Consulta: 18 de enero de 2019].

Enciso, V., \& Roche, C. (2006). Fiscalidad y desarrollo rural en Espańa. Los beneficios fiscales en el mundo rural español. Revista de Economía Pública, Social y Cooperativa, (55), 91-124. Recuperado de https://www.redalyc.org/articulo.oa?id=17405504 [Consulta: 18 de enero del 2019]. 
Federación Colombiana de Ganaderos (FEDEGAN). (2016). Precios de leche en la finca [Boletín]. Recuperado de http://bibliotecadigital.agronet.gov.co/bitstream/11438/8393/1/BolSipsaLeche_ago_2016.pdf [Consulta: 18 de enero de 2019].

Fuentes H., \& Zamudio, A. (2011). IVA: ¿Qué sucede si los bienes y servicios a tasa $0 \%$ se cambian a exentos? Análisis Económico, 26(61), 199-210. Recuperado de https://www.redalyc.org/html/413/41318401012/ [Consulta: 18 de enero de 2019].

Galvis, R., \& Ramírez, M. (2006). El control constitucional de los acuerdos en forma simplificada en Colombia. Un caso de evasión del control. International Law, (8), 11-52. Recuperado de http://ebscohost.ezproxy. uniminuto.edu/login.aspx? direct $=$ true $\& \mathrm{db}=\mathrm{zbh} \& \mathrm{~A}$ $\mathrm{N}=26425314 \&$ lang=es\&site $=$ ehost-live\&scope $=$ site [Consulta: 18 de enero de 2019].

García, C., Torrejón, L., San Alverto, D. \& Del Blanco García, A. (2010). Estudio comparado de los sistemas Tributarios en América Latina (Documento para el Instituto de Estudios Fiscales, y el Ministerio de Economía y Hacienda). Recuperado de http://www.uca. edu.sv/mcp/media/archivo/dd91b6_estudiocomparadodelossistemastributariosenal.pdf [Consulta: 18 de enero de 2019].

González, M., \& Sheila, G. (2015). Reforma hacendaria: La importancia del régimen de incorporación fiscal como medida de desarrollo económico en México y posibles impactos. El Cotidiano, 30(190), 71-76. Recuperado de https://search-proquest-com.ezproxy.uniminuto. edu/docview $/ 1667358015$ ?accountid $=48797 \quad$ [Consulta: 18 de enero de 2019].

Gutiérrez A., \& Tamayo, P. (2017, 27-29 de septiembre). Nuevo régimen fiscal para pequeñas empresas [Presentación en conferencia]. XXII Congreso Internacional de Contaduría, Administración e Informática. México D.F., México. Recuperado de http://congreso.investiga.fca.unam.mx/docs/xxii/docs/6.06.pdf [Consulta: 18 de enero de 2019].
Guerrero, R. (2015). Comparación del régimen de tributación simplificada del artículo 14 ter letra a) de la Ley sobre Impuesto a la Renta con el estudio de la organización para la cooperación y el desarrollo económico sobre tributación de las pequeñas y medianas empresas del año 2015. Revista de Estudios Tributarios, (17), 113-158. Recuperado de https://revistaestudiostributarios.uchile.cl/index.php/RET/article/view/46985 [Consulta: 18 de enero de 2019].

Hernández, S. (2017). El monotributo: análisis de beneficios para los contribuyentes y el progreso de la nación (Tesis de licenciatura, Facultad de Educación a Distancia, Universidad Militar Nueva Granada. Bogotá, Colombia). Recuperado de https://repository.unimilitar.edu.co/bitstream/handle/10654/16751/Her n\%C3\%A1ndezSanchezStephanieFernanda2017. pdf? sequence $=3 \&$ isAllowed $=y$ [Consulta: 18 de enero de 2019].

Instituto de Estudios Estratégicos y Políticas Públicas (IEEPP). (2015). Regimenes Tributarios Simplificados: el caso de las bolsas agropecuarias. ¿Fomentan la equidad tributaria? Managua: IEEPP. Recuperado de https:// www.ieepp.org/media/files/publicacion-6-479.pdf [Consulta: 18 de enero de 2019].

Lemos, R. (2015). Régimen especial de tributación como mecanismo de desarrollo de las pymes brasileńas y los retos de la protección del crédito tributario en los procesos concursales (Tesis de doctorado, Facultad de Ciencias Jurídicas y Sociales, Universidad de Castilla-La Mancha. Ciudad Real, Espala). Recuperado de http://hdl.handle. net/10578/8713 [Consulta: 18 de enero de 2019].

Lattuada, M. (2008). El debate impositivo sobre el sector agropecuario argentino. Anuario Del Centro De Estudios Históricos Profesor Carlos S.A. Segreti, 8 (8), $107-$ 138. Recuperado de https://search-proquest-com. ezproxy.uniminuto.edu/docview/1492929365?accou ntid=48797 [Consulta: 18 de enero de 2019].

Lozano, E. (2009). Tributación de la micro, pequeña y mediana empresa. Revista de Derecho Privado, (42), 3-15. 
Lozano, E. (2014). Tributación de pequeños contribuyentes y regímenes simplificados en Colombia. Artículo corto Universidad de los Andes Facultad de Derecho. Revista de Derecho Privado, (51), 1-14. Recuperado de http://www.redalyc.org/pdf/3600/360033222006. pdf [Consulta: 18 de enero de 2019].

Nagamine, R., Duarte, E., \& Da Silva Bichara, J. (2013). Inclusión de los trabajadores por cuenta propia en el régimen de previsión social en el Brasil. Revista Internacional Del Trabajo, 132 (3/4), 613-622. DOI: https://doi-org.ezproxy.uniminuto.edu/10.1111/ j.1564-9148.2013.00196.x

Organización Internacional del Trabajo (OIT). (2014). Monotributo en América Latina, Los casos de Argentina, Brasil y Uruguay. Lima: OIT, Oficina Regional para América Latina y el Caribe, Programa de Promoción de la Formalización en América Latina y el Caribe. Recuperado de https:/www.ilo.org/wcmsp5/groups/ public/---americas/---ro-lima/documents/publication/ wcms_357452.pdf [Consulta: 18 de enero de 2019].

Presidencia de la República de Colombia. (1989, 30 de marzo). Decreto por el cual se Expide el Estatuto Tributario de los Impuestos Administrados por la Dirección General de Impuestos Nacionales [Decreto Ley 624 de 1989]. Recuperado de http://www.funcionpublica.gov.co/ eva/gestornormativo/norma.php?i=6533 [Consulta: 18 de enero de 2019].

Poblete, C. (2010). Evaluando reformas tributarias en chile con un modelo cge*/Evaluating tax reforms in chile with a cge model. Estudios De Economía, 37 (2), 243284. Recuperado de https://search-proquest-com. ezproxy.uniminuto.edu/docview/859040910?account id=48797 [Consulta: 18 de enero de 2019].

Rodríguez, E. (2014). Tributación de pequeños contribuyentes y regímenes simplificados en Colombia. Revista de Derecho Privado, (51), 1-14. Recuperado de http:// ebscohost.ezproxy.uniminuto.edu/login.aspx?direct $=\mathrm{t}$ rue $\& \mathrm{db}=\mathrm{zbh} \& \mathrm{AN}=97368253 \&$ lang=es $\&$ site=ehost live $\&$ scope $=$ site [Consulta: 18 de enero de 2019].

Rojas, J. (2018). El incrementalismo fiscal, una realidad evidente desde el derecho económico. Contexto, (49), 135-171. https://doi.org/10.18601/01236458. n49.07

Secretaria General del Senado. (2018, 31 de diciembre). Estatuto Tributario Nacional. Recuperado de http:// www.secretariasenado.gov.co/senado/basedoc/estatuto_tributario.html [Consulta: 18 de enero de 2019].

Servicios de Impuestos Internos (SII). (2006). Manual tributario, franquicias y beneficios tributarios para empresas y personas. Recuperado de http://www.sii.cl/ contribuyentes/actividades_especiales/manual_franquicias_tributarias_junio2006.pdf [Consulta: 18 de enero de 2019].

Vidal, F. (2013). Análisis del impacto fiscal del RISE (régimen impositivo simplificado ecuatoriano) en la recaudación tributaria del servicio de rentas internas (Tesis de maestría, Facultad de Ciencias Económicas y Administrativas, Universidad de Cuenca. Cuenca, Ecuador). Recuperado de http://dspace.ucuenca.edu.ec/ bitstream/123456789/378/1/TESIS.pdf [Consulta: 18 de enero de 2019].

Villanueva, D. (2018). Análisis sector agricola y pecuario. Medellín: Universidad EAFIT Recuperado de https:/www.dnp.gov.co/Crecimiento-Verde/Documents/ejes-tematicos/Bioeconomia/Informe\%202/ ANEXO\%201_An\%C3\%A1lisis\%20sector\%20 agr\%C3\%ADcola.pdf [Consulta: 18 de enero de 2019].

Fecha de recepción: 05 de enero de 2021 Fecha de aceptación: 16 de agosto de 2021 Correspondencia: juliana.farfan@uniremington.edu.co hugohass28@hotmail.com 